\title{
Concepções Sociais sobre um Hospital Psiquiátrico em Processo de Fechamento
}

\author{
Pedro Machado Ribeiro Neto ${ }^{1}$ \\ Programa de Pós-Graduação em Psicologia da Universidade Federal do Espírito Santo, \\ Vitória, ES, Brasil \\ Luziane Zacché Avellar \\ Programa de Pós-Graduação em Psicologia, Departamento de Psicologia Social \\ e do Desenvolvimento da Universidade Federal do Espírito Santo, Vitória, ES, Brasil
}

\begin{abstract}
Resumo
O estudo objetiva conhecer as concepções sociais sobre um hospital psiquiátrico em processo de fechamento. Os participantes são habitantes de um conjunto residencial vizinho ao hospital psiquiátrico, onde se localizam três residências terapêuticas (RTs), cujos moradores são ex-internos do hospital. Por meio de perspectiva etnográfica, foram realizadas 22 entrevistas no espaço público do conjunto residencial, abordando as evocações sobre o hospital psiquiátrico, seu fechamento e o destino dos ex-internos. $\mathrm{O}$ hospital psiquiátrico se constituiu como uma referência para os participantes, representado como uma casa de recuperação e concebido como lugar necessário. Os participantes demonstraram descontentamento com o fechamento, mas apresentaram uma postura favorável à sua desativação, fundamentada na convivência com moradores das RTs concebidos como não agressivos. Contudo, os participantes sugerem que as RTs sejam transferidas para locais afastados. Os resultados apontam a necessidade de manter os hospitais abertos ou a criação de outros espaços semelhantes, proporcionando o afastamento social dos moradores das RTs. É preciso discutir as possibilidades para a convivência com ex-internos de hospitais psiquiátricos, no sentido de possibilitar a coexistência entre grupos supostamente diferentes, pois a tendência ao afastamento, como observada, se constitui como um processo necessário para defesa da identidade grupal, mas deve ser combatida.
\end{abstract}

Palavras-chave: Residências terapêuticas, desinstitucionalização, hospitais psiquiátricos, representações sociais, etnografia.

\section{Social Conceptions of a Psychiatric Hospital in the Process of Closure}

\begin{abstract}
The study aims to understand the social conceptions of a psychiatric hospital in closing process. Participants live in a residential neighborhood near to the hospital, where three therapeutic residences (TRs) are located, whose residents are egress of the hospital. Through ethnographic perspective, 22 interviews were realized, addressing the evocations about the psychiatric hospital, its closure and the destiny of the egress. The psychiatric hospital was conceived as a reference to the inhabitants, being
\end{abstract}

Endereço para correspondência: Universidade Federal do Espírito Santo, Campus Universitário de Goiabeiras, Prédio Lídio de Souza, Av. Fernando Ferrari, 514, Vitória, ES, Brasil 29075-910. Fone: (27) 99272-0269. E-mail: mrn.pedro@gmail.com e luzianeavellar@yahoo.com.br

Pesquisa financiada pela Coordenação de Aperfeiçoamento de Pessoal de Nível Superior (CAPES), através da concessão de bolsa de doutorado. 
represented as a halfway house and conceived as a necessary place. The participants showed displeasure with the closure, but at the same time, a favorable position to its deactivation, based on interaction with the former inmates of the hospital that lives in the neighborhood, represented as non-aggressive. Participants suggested that TRs are transferred to remote locations. The representations observed indicate the need of keep the psychiatric hospital open or the creation of other similar spaces, providing the social withdrawal of the egresses. Thus, it is necessary to discuss the possibility for coexistence between supposedly different groups, since the tendency to removal, as observed in this study, can be as a process necessary for the defense of group identity, but must be fought.

Keywords: Therapeutic residences, deinstitutionalisation, psychiatric hospitals, social representations, ethnography.

\section{Concepciones Sociales sobre un Hospital Psiquiátrico en Proceso de Cierre}

\section{Resumen}

El estudio tiene como objetivo comprender las concepciones sociales acerca de un hospital psiquiátrico en proceso de cierre. Los participantes viven en un barrio próximo al hospital, donde se encuentran tres residencias terapéuticas (RTs), cuyos residentes son ex pacientes del hospital. A través de la perspectiva etnográfica, se realizaron 22 entrevistas, cuya guía de la entrevista se dirigió a las evocaciones sobre el hospital psiquiátrico, su cierre y el destino de los ex pacientes. El hospital psiquiátrico fue concebido como una referencia, representado como una casa de recuperación y un lugar necesario. Los participantes mostraron descontento con el cierre, pero al mismo tiempo, una posición favorable para su desactivación, basada en la interacción con los moradores de las RTs, representado como no agresivo. Los participantes sugirieron que RTs son trasladadas a lugares remotos. Las representaciones observadas indican la necesidad de mantener el hospital psiquiátrico abierto o la creación de otros espacios similares, proporcionando el aislamiento social de los egresos. Por eso, es necesario discutir la posibilidad de convivencia con los ex internos de hospitales psiquiátricos, ya que la tendencia a la exclusión puede ser un proceso necesario para la defensa de la identidad de grupo, sino que debe ser combatido.

Palabras clave: Residencias terapéuticas, desinstitucionalización, hospitales psiquiátricos, representaciones sociales, etnografía.

A consolidação das políticas de saúde mental fundamentadas pelos processos de desinstitucionalização da loucura favoreceu o fechamento de hospitais psiquiátricos, e assim, a população outrora confinada passou a coabitar os espaços sociais. Os egressos de longas internações psiquiátricas, sem suporte social e laços familiares, são deslocados para as Residências Terapêuticas (RTs) que, segundo a Portaria 106/Ministério da Saúde, precisam estar inseridas preferencialmente nas comunidades (2000). Mas, quais as concepções dos habitantes das localidades para onde vão os egressos, sobre a existência e o fechamento do hospital psiquiá- trico? Estão cientes da inserção desta população em sua vizinhança?

Este estudo discute as concepções de habitantes de um conjunto residencial onde estão localizadas três RTs, vizinho a um hospital psiquiátrico que foi recentemente desativado, do qual os moradores das RTs são egressos. Para isso, o estudo utiliza o referencial teórico das representações sociais. As representações sociais se constituem como uma forma de pensamento social, um saber compartilhado pelo grupo, construído e transmitido no cotidiano das relações e através das gerações, com finalidade prática. Sua análise é importante, pois funcionam 
delineando os comportamentos sociais (Jodelet, 2005; Jovchelovitch, 2004).

Conhecer as representações sobre o hospital psiquiátrico favorece a problematização da relação estabelecida com os egressos. Além do referencial teórico das representações sociais, o estudo se fundamenta nas considerações provenientes da experiência italiana de desinstitucionalização, considerada fundamental para as transformações da assistência em saúde mental. Desinstitucionalizar significava problematizar os aparatos legislativos, administrativos e científicos que sustentam a existência do manicômio, criados em torno da periculosidade da "doença mental" (Basaglia, 1982; Rotelli, Leonardis, \& Mauri, 2001).

No Brasil, tem sido observada a existência de resistência social sobre o fechamento dos hospitais psiquiátricos e implantação de serviços comunitários de saúde mental, se constituindo como entrave para as políticas nessa área (Ministério da Saúde, 2011). Além disso, pode ser considerada a presença de estigma relacionado à população egressa de longas internações psiquiátricas, pois:

$\mathrm{O}$ fato de estar ligado a um estabelecimento psiquiátrico é realmente determinante, na medida em que implica um status de prisioneiro e a supressão de certos direitos. $\mathrm{Na}$ verdade, é o estado de internamento e não o estado de doente que está na origem de toda uma série de atribuições desvalorizadas ou negativas. (Jodelet, 2005, p. 133)

\section{Objetivos}

O estudo tem como objetivo conhecer as concepções de habitantes de um conjunto residencial sobre um hospital psiquiátrico, e mais especificamente, conhecer as concepções sobre o seu fechamento e sobre o destino dos egressos sem suporte social e laços familiares.

\section{Percurso Metodológico}

Por meio da perspectiva etnográfica, a pesquisa de campo foi realizada no espaço público do conjunto residencial: "a técnica de etnografia de rua consiste na exploração dos espaços urba- nos a serem investigados através de caminhadas 'sem destino fixo' nos seus territórios" (Rocha \& Eckert, 2003, p. 4). A etnografia urbana se pauta na descrição de práticas e saberes de indivíduos e grupos utilizando observação e conversações, caracterizada pela frequência do investigador no campo de estudo, podendo ser uma rua, avenida ou bairro em que, por meio de entrevista e observação sistemática dos cenários e personagens envolvidos, procura as significações decorrentes daquele cotidiano (Rocha \& Eckert, 2003).

A pesquisa de campo foi conduzida pelo autor principal deste artigo, totalizando seis momentos de imersão em campo, entre outubro de 2011 e fevereiro de 2012, em dias e horários diversificados, com duração entre duas horas a quatro horas e meia cada ida a campo. A inserção no campo de estudo foi facilitada porque o pesquisador possui experiência de pesquisa anterior no hospital psiquiátrico em questão e também no conjunto residencial, desenvolvidas na graduação e no mestrado, respectivamente.

O conjunto residencial onde foi realizada a pesquisa de campo caracteriza-se como um local composto basicamente por casas residenciais e alguns poucos estabelecimentos comerciais, entre os quais, se destaca uma padaria, local em que há circulação de pessoas e dos próprios moradores das RTs, visto que em seu andar superior funciona uma RT. A padaria se localiza na rua principal que dá acesso ao conjunto residencial e fica em frente à pracinha do local, conjuntura que favoreceu a realização de entrevistas naquelas imediações.

Foram realizadas 22 entrevistas, registradas com equipamento de áudio e transcritas integralmente. As entrevistas foram realizadas nas ruas principais e adjacentes do conjunto residencial em estudo, nas imediações das casas dos participantes e também em alguns estabelecimentos comerciais. Os participantes foram selecionados de forma aleatória, durante o percurso do pesquisador pelo bairro. Vale ressaltar que, em alguns momentos, as entrevistas foram realizadas com duas ou mais pessoas.

O hospital psiquiátrico era denominado Hospital Adauto Botelho, e assim, o roteiro da entrevista foi composto por tópicos que abarca- 
ram: as evocações em relação à palavra "Adauto", as concepções sobre seu fechamento e sobre o destino dos egressos sem família. Além das entrevistas, outras experiências do pesquisador em campo possibilitaram a aquisição de dados complementares, como a participação em um churrasco e em uma confraternização religiosa a convite dos participantes, favorecendo a inserção no cotidiano.

O material transcrito foi analisado mediante o processo de Análise de Conteúdo Temática, como postula Minayo (2004). Inicialmente, foi realizada a leitura exaustiva da totalidade das entrevistas. Posteriormente, algumas temáticas se destacaram e foram organizadas em categorias que serviram de substrato para a configuração dos resultados. Por fim, foi realizada a leitura e análise dos registros de diário de campo.

Em conformidade com a Resolução 466 que regulamenta a pesquisa com seres humanos (Ministério da Saúde, 2012), todos os participantes consentiram em sua participação, puderam abandonar a entrevista caso assim desejassem, tiveram garantia de que sua identidade seria mantida no anonimato e foram esclarecidos de que as informações concedidas poderiam ser apresentadas em eventos e publicadas em revistas científicas.

\section{Resultados}

\section{Evocações e Associações em Relação ao Hospital Psiquiátrico}

As evocações possibilitaram a constituição de três eixos temáticos: o primeiro se refere às definições sobre o hospital psiquiátrico; o segundo foi composto por evocações que sugerem uma apreciação positiva do hospital; e o terceiro, formado por avaliações negativas da instituição. Após a exposição dos três eixos, são apresentados os resultados referentes às representações sobre o fechamento e sobre o destino dos egressos do hospital psiquiátrico.

No contexto do primeiro eixo, os termos "doido" e "recuperação" foram evocados com maior frequência: "falam que é os doidos que ficam lá, mas todo mundo tem a chance de recuperar, né", "o Adauto é uma casa de recupe- ração, prá tentar recuperar alguns indivíduos que agem de forma diferente ao que a sociedade imagina". Uma participante definiu o hospital psiquiátrico como "casa de doido" e demonstrou dificuldade em citar outras evocações: " $E u$ só falaria isso. Eu fui nascida e criada aqui, e toda vida... eu fiquei sabendo que era a casa dos doidos, é a pessoa desequilibrada que vive $a l i$ ". Além disso, segundo outro participante, "lá em cima é onde ficava os doidos que batia nos outros, tinha um amigo que trabalhou lá... que lá o pessoal batia nos outros, agredia". Um dos participantes discorreu sobre aspectos históricos ligados ao hospital psiquiátrico e características da população atendida:

Antigamente o Adauto era tratado como aqueles paciente, é... pobres, é... vagabundos, os próprio psiquiátricos mesmo, eles eram conhecidos como doidos, né?! Como doido não, como... que eles eram possuído por um diabo, alguma coisa ruim. Então eu acho que o Adauto é conhecido como... é utilizado por pessoas drogadas também, entendeu, por que o Adauto tem o quê, tem pessoas drogadas, viciadas, têm pacientes psiquiátricos que realmente têm aquele problema de cabeça.

Ressalta-se que a configuração em eixos temáticos foi elaborada no sentido de facilitar a visualização dos dados. Contudo, foi possível observar a presença de dois, às vezes três eixos em uma única sentença, mais especificamente, na concepção do hospital psiquiátrico como manicômio e inferno, e ao mesmo tempo, como uma casa de amparo e recuperação: "Bom, todo mundo fala que aquilo é um inferno, mas eu acho que não, né. Acho que aquilo lá é uma casa de recuperação. Uma casa prá recuperar pessoas idosas, que tão lá, tão com depressão, crise, né". Nesse sentido, outro participante relatou:

A primeira coisa que vem na cabeça é manicômio, lugar prá gente que tem distúrbio, transtorno mental, mas, prá definir em cinco palavras assim eu diria que... é tratamento, psiquiatria, apoio psicológico, amparo, um trabalho social forte lá dentro também.

No contexto do segundo eixo, caracterizado por valorações positivas sobre o hospital psiqui- 
átrico, a expressão "problema" foi recorrente, configurando o hospital psiquiátrico como uma espécie de solução para determinadas situações:

Você promover o tratamento prá essas pessoas de distúrbio mental, você evita outros problemas, é, familiares mesmo, e até problemas mesmo... questões de rua, que muitas vezes a familia abandona essas pessoas na rua ai e acaba fazendo maiores problemas mesmo, assim prá sociedade.

Existem muitas famílias que, às vezes com o problema em casa, querem se livrar do problema, ou às vezes não aguentam, não conseguem lidar com aquelas pessoas problemáticas em casa, preferem colocar no hospital. Então, eu diria assim, é. compromisso, dedicação, amor, dos profissionais para com as pessoas deficientes.

A apreciação de certo modo positiva relacionada ao hospital psiquiátrico foi igualmente observada na temática da drogadição: "um local que as pessoas precisam. Uns têm problemas psiquiátricos, outros têm problemas com drogas, entendeu, envolvimento com droga, então têm vários tipos de doenças que é tratado lá que eu acho importante". Além disso, o hospital psiquiátrico apareceu como uma opção frente ao abandono: "pessoas que foram abandonadas dentro de casa, e tiveram como opção ser levadas prá lá". Nessa esteira, foi observada uma estreita relação entre o hospital e o conjunto residencial:

O Hospital Adauto Botelho aqui prá nós aqui é uma referência, né... uma referência aqui pro nosso bairro. Todo mundo que liga fala assim: "pô, eu quero ficar perto do Adauto". Pessoal pega um ônibus, não sabe, então tem como referência o Adauto Botelho. É, "eu moro próximo ao Adauto Botelho", entendeu.

Delineando essa relação de proximidade e familiaridade entre o conjunto residencial e o hospital psiquiátrico, vale destacar que alguns participantes relataram que possuem parentes que trabalharam no hospital, um participante trabalhou na instituição e outros afirmaram terem ido ao hospital, mas por outros motivos.

Contudo, o terceiro eixo foi constituído por apreciações negativas ou desfavoráveis sobre o hospital psiquiátrico, porém, em menor proporção em comparação ao eixo anterior. Um participante argumentou que no hospital psiquiátrico era praticado o "tratamento de choque", assim como "batiam em muitos pacientes". Uma participante se reportou a uma ocasião em que esteve nesta instituição:

A gente vê que é uma coisa triste, que aceitavam até criança. Ai eu era muito nova, não entendia o que era esse negócio de pessoas com problema de cabeça, aí eu perguntei até a enfermeira, por quê que aquelas crianças tava ali, outros presos igual a prisioneiro na grade mesmo, né. Ai foi que a enfermeira falou comigo que aquelas crianças tinham o mesmo problema dentro da cabeça igual os outros.

No contexto dessa avaliação desfavorável do hospital psiquiátrico, uma participante argumentou sobre a medicalização a qual os internos estariam submetidos:

Eles botam muito remédio prá eles tomarem, né, com certeza, e isso acho que afeta mais ainda. Eles tão lá prá se recuperar, só que eu creio que eles tomando esses remédios, parece que vão piorando mais, não sei. Eles tão lá prá se recuperarem, mas... prá mim não se recuperam tão bem assim, né, por que do remédio que eles ficam dando a eles.

\section{O Fechamento do Hospital Psiquiátrico}

Os participantes sabem do fechamento do hospital psiquiátrico, e diante disto realizaram questionamentos: "Essas pessoas que saem de lá tão recuperadas?", "E aqueles agressivos, vai prá onde?", "Vai ter outro hospital no lugar dele?", "Como é que vai ficar os pobres, os coitados que depende deles aí prá remédio... prá fisioterapia... prá psicólogo?". Além disso, os termos "precisa", "necessita" e "depende" foram recorrentes, no sentido de que muitas pessoas precisariam da instituição em funcionamento: "Mas eu não queria que fechasse, não, muita gente depende daquilo, precisa". Uma participante afirmou, sobre o fechamento:

Ah, eu acho errado! Eu acho que eles têm que fazer mais clínicas prá botar esse tipo 
de gente, não acabar com o que tem. É eles... melhorar, para que eles possam... ter um conforto melhor ali em cima. Tem tanto terreno ai, o Adauto poderia fazer muito bem uma casa, prá eles ter um lazer, eles não tem um lazer aqui no conjunto.

Foi igualmente observada a defesa da manutenção do hospital psiquiátrico em funcionamento, diante da necessidade de intervenção em situações de agressividade. Nesse sentido, destaque para a diferenciação entre o que seriam dois grupos: "Tem o Adauto prá aquelas pessoa em avanço, perigoso, tudo bem. Têm muitos pessoal ali que tem problema de nervo que precisa mais de carinho do que praticamente de um hospital". Seguem as falas ilustrando esta distinção entre grupos:

O primeiro tratamento tinha que ser lá! Imagina, se eu pegar um doido aí que sai batendo, pegando as coisas dos outros, e jogar numa quadra, num bairro com um monte de gente? Esses daqui a gente vê que eles não são agressivos, não são nada. Mas têm uns doido aí que no seu primeiro estágio são agressivos.

A pessoa doente da cabeça é perigoso, tem uma força tão enorme... eu já vi dentro de uma igreja uma mulher ficar louca! Ninguém tava conseguindo segurar ela! Precisava apanhar a corda e laçar ela como que se laça um animal! Tem que ter separação, por que onde vai fazer isso? Se tem ainda esse tipo de pessoa que fica assim, né. No entanto, um participante destacou a necessidade do hospital psiquiátrico em funcionamento para pessoas com "transtorno psicológi$c o$ ", diferenciando os internos do hospital, que nesse caso não seriam perigosos, em comparação com os internos de um manicômio judiciário, que por sua vez seriam dotados de periculosidade:

Confundem o Adauto com manicômio, $e$ não é verdade, o Estado tem o manicômio judiciário dele, que fica lá em Cariacica Sede, que é prá tratar mesmo essas pessoas de periculosidade social, envolvidas em crime, mas que têm distúrbios mentais. O Adauto Botelho já trabalha mais com essas pessoas mais dóceis, pessoas que tem transtornos psicológicos, mas não representa perigo eminente prás pessoas, prá sociedade em geral.

Contudo, alguns participantes apresentaram postura favorável ao fechamento do hospital psiquiátrico, tendo como fundamento de suas análises a experiência concreta com os moradores das RTs no conjunto residencial: "Pelo que eu vejo as pessoas no convivio geral aqui no conjunto, eu acho que não haveria necessidade de estarem tratando numa clínica fechada". Ou, segundo outro participante:

. . desde quando eles vieram prá cá, nada mudou prá mim não, continua sendo a mesma coisa, não aconteceu nada, nem, até melhorou, que tem certas pessoas ai que é pior do que eles. Eles não falam mal de ninguém, fica quietinho no canto deles... não vi diferença.

\section{O Destino dos Egressos do Hospital Psiquiátrico Sem Vínculo Familiar}

Nesta questão especificamente, os participantes se reportaram em veemência à presença das RTs em sua vizinhança, ressaltando inclusive sua quantidade aproximada, com destaque para a frequência do termo "aqui": "Eles vêm pro conjunto, que têm três aqui já! Tinha quatro!". Nesse encalço, um participante discorreu: "Aqui mesmo é um exemplo de onde está ocorrendo essa acomodação desse pessoal de lá. Eles alugam casa, têm umas cinco casas aqui que são especificamente prá acomodar esse pessoal que tá em tratamento no Adauto Botelho".

Ao discorrerem sobre o destino dos egressos sem vínculo familiar com o fechamento do hospital psiquiátrico, principalmente no momento em que esse destino é a sua própria vizinhança, os participantes sugeriram a criação de um espaço mais amplo do que as RTs para abrigar essa população, em benefício dos moradores das RTs:

Uma casa com quintal que eles pudessem andar, não preso igual tá ali. Se você passa na pracinha você vê eles, um vai prá lá outro vem prá cá, o dia todinho. Prá mim eles tão fazendo errado, deveriam arrumar 
um lugar que eles pudessem ter quintal prá tomar sol, que eles não tomam sol ali.

Defesa semelhante de um lugar mais espaçoso e fora dos limites do conjunto residencial foi realizada por um participante, imaginando um espaço com: "jardim, uma área de lazer prá eles". Nesse percurso, outro participante foi além e criou um conceito em relação ao que seria um espaço ideal destinado para aquela população, ao qual denominou de "casas-chácara":

...eu até sugiro que, por exemplo, as casas que o Estado usa aqui, com o intuito de ressocializar, fizesse essas casas em áreas... maiores, onde os próprios internados tivesse a opção de fazer uma terapia trabalhando . . Que eles tivessem algo prá fazer, é... casas-chácara! Tivesse aquela terapia de plantar, de colher, de tirar o fruto, de vender, eu penso assim, usando áreas de plantio.

\section{Discussão}

\section{As Concepções sobre o Hospital Psiquiátrico}

Para discutir as concepções de um grupo de habitantes sobre o hospital psiquiátrico, o estudo utilizou o referencial teórico das representações sociais. Segundo Jovchelovitch (2004), as representações se relacionam ao contexto psicossocial, cultural e histórico de sua origem, ilustrando a relação fundamental entre as formas de saber e o lugar onde são elaboradas. Para debater a multiplicidade das representações, Jovchelovitch (2004) utiliza o conceito de "polifasia cognitiva", que se refere à variabilidade do saber presente nas formas representacionais. Nesse sentido, um indivíduo ou grupo pode apresentar um discurso contraditório sobre determinado assunto, de acordo com interesses e funções às quais as representações elaboradas preenchem: "A dinâmica da forma representacional lhe permite a variação e a capacidade de conter tantas racionalidades quantas necessárias à variedade infinita de situações socioculturais que caracterizam a experiência humana" (p. 27).

As representações sociais permitem compreender as informações provenientes da reali- dade cotidiana e assim elaborar formas de lidar com as situações sociais. Isso pode ocorrer, por exemplo, através da criação de estratégias de defesa sobre uma ameaça, possibilitando o controle ou afastamento dessa insegurança. Além disso, tais estratégias permitem a manutenção da identidade grupal positivamente avaliada de um grupo de referência: "No plano da afiliação grupal nas relações cotidianas, os indivíduos possuem representações acerca de sua própria realidade, as quais poderão orientar os comportamentos possíveis nas suas interações com os demais grupos e nortear as identificações/diferenciações sociais" (Bonomo, 2010, p. 72). Assim, as representações sociais elaboradas pelos participantes desta pesquisa podem servir como orientação para os comportamentos sociais, por exemplo, na tentativa de enfrentamento de uma situação conflituosa, ilustrada pelo fechamento do hospital psiquiátrico, assim como, na preservação e constituição de uma identidade grupal positivamente avaliada.

A literatura sobre a desinstitucionalização italiana destaca que os hospitais psiquiátricos são em geral espaços de violação de direitos humanos (Basaglia, 1982; Rotelli et al., 2001). Apesar desta afirmação, foi possível observar no discurso dos participantes uma representação positiva do hospital psiquiátrico, de modo contrário ao que preconizam os autores italianos e a própria legislação brasileira referente às políticas de desinstitucionalização (Ministério da Saúde, 2000, 2011).

De forma a corroborar os resultados aqui encontrados, Maciel, Barros, Camino e Melo (2011) destacam a existência de estudos que apresentam concepções positivas sobre os hospitais psiquiátricos, principalmente por parte das famílias dos internos:

Tais pesquisas evidenciaram representações positivas do hospital psiquiátrico, ancoradas no fato de que o hospital trata e cuida do doente mental e que a presença do doente em casa gera uma tensão e um clima de medo, compartilhado pelos familiares, legitimando a hospitalização. (p. 201)

Aqui se apresenta um aspecto importante: estas afirmações apontam a necessidade de maior 
problematização acerca do hospital psiquiátrico e das representações em torno deste, pois, trata de uma instituição falida e que deve ser abolida, tendo em vista o caráter de violência e violação de direitos humanos presente nestes estabelecimentos (Basaglia, 1982), ao contrário, portanto, do que relataram os participantes desta pesquisa.

$\mathrm{O}$ conjunto residencial em estudo foi fundado cerca de duas décadas após a inauguração do hospital psiquiátrico de sua vizinhança, tendo crescido às margens deste. Por serem vizinhos, têm uma história construída: "é uma referência, $n e ́ "$. Desse modo, em quase sessenta anos de existência, o hospital acaba por fazer parte do cenário da vida daquele local, compondo a paisagem cotidiana. Isso pode favorecer um sentimento de familiaridade em relação ao hospital, e consequentemente, sua valorização. Essa discussão sobre valorização do local de origem foi abordada por Rivas e Inostroza (2003), em estudo sobre identidade regional. Em pesquisa em uma região chilena desfavorecida economicamente, os autores observaram que os participantes enalteceram os recursos naturais do local de origem, destacando a beleza da paisagem de onde habitavam, tendo em vista uma série de condições adversas presentes na vida daquela população e que não valeriam a pena serem destacadas: "Nossos participantes têm destacado a importância das características regionais com uma valência positiva e têm relegado para segundo plano aquelas que têm uma conotação negativa" (p. 90).

Assim, a identidade regional estaria relacionada ao local de nascimento das pessoas. Nas devidas proporções, a discussão sobre identidade regional pode ser utilizada neste estudo, haja vista a aparente necessidade dos participantes de destacar favoravelmente o hospital psiquiátrico, demonstrando essa estreita relação entre eles e a instituição psiquiátrica, como observado por Moreira (2007): "há um grande número de residentes do entorno que têm ou tiveram suas vidas entrelaçadas de alguma maneira com o hospital" (p. 92). O hospital psiquiátrico da vizinhança dos participantes integra o cenário natural daquele local, sendo cognitivamente transformado em parte da paisagem. Entendendo o hospital como componente do meio físico, cultural e histórico dos participantes, como integrante do local de origem, a valorização é imprescindível no sentido de ". . . preservar o meio em que se enraíza a sua própria identidade” (Jodelet, 2005, p. 353).

Os participantes conceberam o hospital psiquiátrico como uma casa de recuperação de doidos. Em outra direção, Leonardis, Mauri e Rotelli (2001) argumentam que:

. . . o manicômio não é uma casa: se vai ou se está no manicômio por falta de alternativas de casas, de dinheiro, de relações de apoio, de recursos para viver e para se reconhecer no tecido das trocas sociais. (p. 72).

É nesse sentido que os reformadores italianos passaram a declarar os hospitais psiquiátricos como locais inabitáveis, proporcionando sua abertura e o cuidado realizado nos espaços da cidade. Apesar dessa afirmação dos manicômios como locais inabitáveis, os participantes deste estudo representaram o hospital psiquiátrico como uma casa e, além disso, como solução para diversos problemas, de ordem familiar, social, mental ou com drogas, intervindo sobre "alguma coisa ruim", o que, mais uma vez, denota a necessidade de aprofundar a discussão a respeito deste, no sentido de proporcionar o entendimento compartilhado sobre a importância de sua superação. Dessa maneira, pode-se dizer que o hospital psiquiátrico se constituiu como um alívio para situações conflituosas, evitando os transtornos de diversas ordens e assumindo caráter positivo na visão dos participantes, uma proteção contra "maiores problemas mesmo, assim, prá sociedade".

Mesmo com certa apreciação positiva da instituição psiquiátrica, alguns participantes destacaram aspectos negativos, como a estrutura precária, a violência física e a medicalização exacerbada as quais os internos estariam submetidos. Sobre essa questão, Lima (2005) resgata a história do hospital psiquiátrico em questão e destaca que, uma vez admitido, o interno era imediatamente medicado visando impedir incômodos e lidar com eventuais crises, e assim, a assistência psiquiátrica nesse contexto “. . . foi marcada por um tradicionalismo nas ações, representado por uma terapêutica baseada, quase que exclusivamente, na medicação, contando com o uso do eletrochoque e de 'quartos-fortes' 
ou 'cubículos' destinados aos pacientes mais 'agitados"' (Lima, 2005, p. 83).

Apesar das afirmações sobre a medicação como importante forma de controle no hospital psiquiátrico, na pesquisa de Jodelet (2005) a medicação era concebida de forma negativa pelas famílias que hospedavam ex-internos de hospitais psiquiátricos em suas casas, pois os egressos serviam como força de trabalho e a medicação era um empecilho para isso. Ao mesmo tempo, a medicação trazia a associação dos egressos com a imagem do "doente nervoso", capaz de maldade e evitado pelas famílias. Mesmo que em contextos diferentes, a medicalização sobre os ex-internos do hospital psiquiátrico também foi representada negativamente pelos participantes, entendida como um fator que impede a recuperação: "vão piorando cada vez mais".

\section{As Concepções sobre o Fechamento do Hospital Psiquiátrico}

De modo contrário ao que preconizam os movimentos de desinstitucionalização (Basaglia, 1982; Ministério da Saúde, 2000, 2011; Rotelli et al., 2001), ficou evidente o descontentamento dos participantes com o fechamento do hospital psiquiátrico: "eu não queria que fechasse". Uma participante ilustrou sua insatisfação com a vinda dos ex-internos para a vizinhança, a partir do fechamento do hospital e sugeriu: "tem tanto terreno ai, o Adauto poderia fazer muito bem uma casa". Em suas respostas, os participantes se remetiam aos internos para discorrer sobre o fechamento, questionando se estariam recuperados, principalmente em função da existência de internos que seriam supostamente agressivos, demonstrando desconforto com o fechamento e ilustrando que as representações sobre o hospital psiquiátrico estão, em parte, fundamentadas na ideia da agressividade dos internos. Nessa discussão, Pacheco, Almeida e Rodrigues (2007) realizaram pesquisa etnográfica em Campinas sobre a reforma psiquiátrica e destacaram a existência de resistências à transformação dos hospitais psiquiátricos em serviços comunitários, fundamentadas na ideia da ameaça social: "Muitos creem que os manicômios serão fechados e que os loucos ficarão soltos pelas ruas, sem tratamento, ameaçando a população e a ordem social" (p. 125).

Foi possível observar no discurso dos participantes a criação de dois grupos distintos: de um lado, internos que seriam "agressivos", e de outro, internos "não agressivos", os quais estariam recuperados e precisariam "mais de carinho do que de hospital". Assim, foi observada a representação de duas formas principais de loucura, uma de certo modo mais tolerável, recuperada, sendo possível sua convivência no conjunto residencial, e outra que seria perigosa, sendo necessária sua separação através do hospital psiquiátrico. De tal modo, a existência da representação dessa periculosidade atribuída a certas formas de loucura, favorece a ideia da necessidade de manter o hospital psiquiátrico em funcionamento.

Todavia, a representação da loucura a partir dessa dicotomia entre agressivos e não agressivos, principalmente na afirmação de que "os daqui não são perigosos", parece servir para facilitar a aceitação social dos egressos de longas internações por parte dos habitantes do conjunto residencial. Para Jodelet (2005), a periculosidade é um tema central na discussão sobre o destino social do louco. Em sua pesquisa, observou a constituição de dois polos, expressos pela diferenciação entre o "retardado", que era assemelhado à criança e tolerada sua convivência, e o "nervoso", não submisso e incapaz para o trabalho, podendo atentar contra a integridade das pessoas à sua volta, dificultando sua permanência nas instalações. Esse processo servia para que as famílias pudessem avaliar a possibilidade de permanência destes em sua propriedade: "Nesse ponto de vista, dois tipos de doentes são rapidamente julgados: num sentido positivo, o retardado, e num sentido negativo, o muito nervoso" (p. 209).

De modo aproximado, os dados deste estudo mostraram que os internos do hospital psiquiátrico são representados de forma positiva e de certo modo aceitos, no entanto, a partir do momento em que fazem parte do grupo dos participantes, isto é, quando passam a morar na vizinhança: "Esses aqui a gente vê que não são agressivos, mas tem doido que é perigoso". Assim, o esta- 
tuto de agressividade é destituído do ex-interno, sendo deslocado para uma imagem simbólica do "doido que é perigoso". Além disso, uma participante afirmou ter presenciado uma mulher ficar louca na igreja, dotada de "uma força tão enorme" que foi preciso laçá-la "como se laça um animal". Para casos assim, seja representado pela ideia do doido perigoso ou pela experiência concreta da mulher na igreja, seria preciso o hospital psiquiátrico como "primeiro tratamento", uma vez que "tem ainda esse tipo de pessoa que fica assim".

Um dos participantes estabeleceu, por sua vez, uma diferenciação entre os internos do hospital psiquiátrico em questão e internos de um manicômio judiciário, onde ficariam as "pessoas de periculosidade social", ou seja, "envolvidas em crime, mas que têm distúrbios mentais". Assim, o participante deslocou o signo da periculosidade, outrora sobre os internos do hospital, para fronteiras mais distantes, "lá em Cariacica Sede". Essa produção da alteridade, com a atribuição do sinal da periculosidade em grupos distantes, pode ser interpretada como uma tentativa de favorecimento grupal, afastando o traço negativo para outro grupo. Em outra direção, uma minoria afirmou não ver problema com o fechamento do hospital psiquiátrico, pois os ex-internos, na condição de moradores das RTs, seriam "quietinhos no canto deles", em comparação com "certas pessoas ai pior". Isso pode ilustrar a aceitação destes na comunidade, mas por outro lado, esse "quietinho no canto deles" pode significar um risco aos objetivos das políticas de saúde mental, ilustrando a presença de um controle considerável e revelando também um aspecto que sugere essa separação simbólica, no momento em que permanecem sem voz e "no canto deles", mesmo que vizinhos. No entanto, tais representações podem servir como estratégia cognitiva para possibilitar certa comodidade ao grupo, diante da coexistência com a diferença, pois produz uma sensação de segurança, o conhecimento de que estão controlados e permanecem à parte.

Jodelet (2005) observou que as representações sociais sobre os egressos possibilitavam estratégias de distanciamento e separação, constituindo uma defesa da identidade grupal. O maior risco para a comunidade, naquele contexto, não se constituía na periculosidade atribuída aos ex-internos, mas na destituição da diferença que cognitivamente separava os grupos, os civis dos "malucos". Assim, aquela comunidade, “. . . visando o melhor para os seus interesses e sua defesa, inventou uma instituição social que permite integrar, sem incorporá-lo a si, um grupo exógeno" (p. 352). De forma semelhante ao observado pela autora, os participantes deste estudo parecem integrar os ex-internos do hospital psiquiátrico, contudo, não de forma plena, sem incorporá-los definitivamente como iguais. Porém, isso pode ser interpretado como um mecanismo de defesa grupal, na medida em que ". . . cada um pensa e age como representante e defensor do seu grupo" (Jodelet, 2005, p. 253).

\section{As Concepções sobre o Destino dos Egressos Sem Vínculo Familiar}

Os participantes estão cientes que o conjunto residencial é destino de alguns ex-internos do hospital psiquiátrico, demonstrando conhecimento sobre a presença das RTs na vizinhança, entendidas como extensão do tratamento hospitalar. Alguns participantes destacaram a necessidade de que as RTs saiam do conjunto, mediante as justificativas de que os ex-internos ficariam presos nas RTs, não tomariam sol e não teriam lazer. Assim, seria preciso um espaço maior com jardim e com algo para fazer, uma "terapia trabalhando": plantar, colher e vender o fruto. Para isso, um dos participantes deu nome ao que seria o espaço ideal: casas-chácara. Nesse sentido, foi possível observar no estudo de Leão e Barros (2008) a ideia sobre a necessidade de um espaço destinado aos usuários de saúde mental em regiões isoladas da cidade, como sugeriu um profissional de serviço psicossocial: "Um espaço mais amplo, térreo, uma chácara, onde o pessoal tenha um espaço, onde possa ter uma quadra" (p. 101). Dessa maneira, a visão do profissional citado se aproxima da concepção dos participantes desta pesquisa, no sentido que estabelece a necessidade de uma chácara para esta população, o que constitui um aspecto que demanda debate, pois incide contra os princípios das políticas de desinstitucionalização (Ministério da Saúde, 2000, 2011). 
A representação sugerindo a inserção daquela população em chácaras, locais agrícolas ou afastados do contexto social urbano se aproxima da ideia que associa a terapêutica à natureza, pois, já no século XIX, a construção dos hospitais psiquiátricos respondia a duas questões principais: proteger a sociedade dos loucos, e também à própria terapêutica, em que os espaços ligados ao ambiente da natureza seriam mais propícios ao tratamento da alienação mental, ao passo que a vida urbana era concebida como uma espécie de estímulo aliciador das perturbações mentais. Por isso os hospitais psiquiátricos foram construídos em áreas afastadas ou com jardins em seu interior, sendo alguns inclusive caracterizados como hospitais-colônia, a exemplo do hospital psiquiátrico em questão. Nesse contexto, ao contrário dos espaços fechados dos hospitais, a natureza era reconhecida como local potencialmente terapêutico, sendo comumente prescritos retiros, um tipo de exílio do mundo da cidade, e, além disso, as plantas arquitetônicas iniciais dos primeiros hospitais psiquiátricos foram elaboradas de forma que cada enfermaria tivesse vista para um jardim (Foucault, 2006; Venâncio, 2011).

Desse modo, a concepção dos participantes pode estar associada ao saber científico, historicamente unindo a terapêutica da loucura ao isolamento do contexto urbano, e ao mesmo tempo, com a própria história do hospital psiquiátrico em questão, uma vez que era caracterizado como hospital-colônia, originalmente construído em área afastada. Em outras palavras, o discurso dos participantes assume uma direção que suscita maiores reflexões por parte da comunidade acadêmica, gestores e profissionais envolvidos, pois sugere que os ex-internos, uma vez localizados em sua vizinhança, retornem para o que seria um hospital-colônia, o que constitui dificuldade para a reintegração social dos moradores das RTs.

A representação que sugere o afastamento das RTs se apresenta como um obstáculo à reintegração social dos ex-internos de hospitais psiquiátricos. Assim, no momento em que os hospitais psiquiátricos são fechados, é criada a ideia de um local para exercer sua função, mesmo que se remetendo aos antigos conceitos, se assemelhando aos primeiros hospitais psiquiátri- cos do tipo colônia agrícola, representado pelas casas-chácara. Porém, essa ideia da construção de um local distante para os ex-internos se constitui como uma tentativa de defesa da identidade grupal, o que ilustra a complexidade dos processos de desinstitucionalização. Nessa direção, Jodelet (2005) observou em seu estudo que as representações sociais criadas pelas famílias sobre os ex-internos de hospitais psiquiátricos serviam para manter a distância necessária para a sobrevivência da identidade grupal da comunidade. A resistência ao convívio não foi tanto em relação à periculosidade atribuída aos egressos, mas ao risco de que estes fossem incorporados de forma plena ao grupo.

Sob esta premissa, não seria a periculosidade historicamente atribuída aos loucos - acentuada com o fechamento dos hospitais psiquiátricos - a razão maior da necessidade de estabelecimento de estratégias cognitivas e concretas de separação e afastamento, mas o risco de que haja uma fusão das identidades, o medo de que os ex-internos do hospital psiquiátrico sejam incorporados ao grupo dos participantes, e de certo modo, confundidos com estes. Nessa ótica, seria preciso preservar a diferenciação entre os grupos para manter a identidade grupal, e isso pode ser alcançado mantendo o hospital psiquiátrico aberto, até porque, este historicamente foi uma referência para o conjunto residencial, compondo a paisagem local e constituindo a identidade daquele grupo que vive na vizinhança do hospital.

A necessidade de manter o hospital psiquiátrico aberto, assim como, da construção de uma chácara para comportar os egressos do hospital psiquiátrico, pode ser uma tentativa de lidar com a alteridade representada pela loucura, que se torna vizinha e passa a fazer parte do ambiente dos participantes, ameaçando a identidade grupal com o risco de sua fusão, de sua desintegração, diluindo-se e tornando parte daquele grupo. Contudo, é preciso ressaltar que a necessidade de preservar a identidade grupal, como observada neste estudo, favorece a exclusão dos ex-internos do hospital psiquiátrico, o que incide contra os princípios da desinstitucionalização (Basaglia, 1982; Ministério da Saúde, 2000, 2011; Rotelli et al., 2001) e, por isso, trata de uma lógica que necessita ser combatida. 


\section{Considerações Finais}

O estudo discutiu as concepções sociais sobre um hospital psiquiátrico, no momento em que as políticas de saúde mental preconizam o fechamento destas instituições e direcionam o cuidado para os bairros. A perspectiva etnográfica se mostrou apropriada aos objetivos propostos, possibilitando a apreensão de processos que não estariam tão evidentes nas entrevistas, como por exemplo, no esforço por parte dos participantes em transmitir uma imagem favorável do hospital psiquiátrico, assim como, no desgosto em seus semblantes quando discorriam sobre o fechamento, como se estivesse sendo praticada alguma covardia: "eu não queria que fechasse".

Com os dados deste estudo, foi possível observar a contradição presente no discurso dos participantes, de modo a ilustrar a possibilidade para a convivência com as RTs a partir da interação cotidiana com seus moradores, e ao mesmo tempo, evidenciando a necessidade de que as RTs sejam afastadas do espaço urbano para outros locais, como uma casa-chácara, em benefício dos ex-internos: "aquela terapia de plantar, de colher, de tirar o fruto, de vender".

Alguns participantes aceitaram com naturalidade o fechamento, pois os ex-internos que vivem nas RTs foram representados como "não perigosos". Mas, se os egressos que vivem no conjunto não são agressivos, qual seria o motivo do afastamento, ilustrado pela "casa-chácara"? Com base no referencial das representações sociais, pode ser afirmado que o motivo deste distanciamento seria a proteção da identidade grupal, pois o que está em jogo é a identidade do grupo obrigado a receber os egressos do hospital psiquiátrico.

De fato, o hospital psiquiátrico em questão é uma referência para a vizinhança, faz parte da vida dos participantes, constituindo sua identidade e, nesse sentido, seu fechamento significaria um golpe na imagem grupal. Dessa forma, a representação favorável do hospital psiquiátrico funciona como fortalecimento da identidade do grupo, além de possibilitar essa separação concreta de uma ameaça real ou simbólica, consti- tuindo um lugar, um destino social para os egressos, mas fora do conjunto residencial.

A tendência ao afastamento das RTs e de seus moradores ilustra a dificuldade dos processos de desinstitucionalização e, mais especificamente, da reintegração social de ex-internos de hospitais psiquiátricos, de forma semelhante ao que foi apontado pelo Ministério da Saúde (2011). Essa rejeição social em relação às RTs precisa ser problematizada e também revertida, o que pode ser alcançado por meio da continuidade de estudos neste campo, assim como, por práticas de conscientização da sociedade, principalmente da vizinhança das RTs. Existem aspectos favoráveis que ilustram as possibilidades da reintegração social, no entanto, as políticas de desinstitucionalização ainda encontram pouca adesão da sociedade e enfrentam inúmeros desafios, como demonstraram os resultados desta pesquisa.

Além disso, a literatura sobre a desinstitucionalização italiana indica que a periculosidade atribuída ao louco seria a chave mestra a sustentar os manicômios, porém, com base nos dados deste estudo, as concepções que associam os egressos do hospital psiquiátrico à agressividade e aquelas que sugerem benefícios em seu afastamento, permitem a defesa da identidade grupal na medida em que possibilitam estratégias de distanciamento e separação desta população em relação ao grupo de origem e de referência dos participantes, evitando assim o risco de entrelaçamento e fusão entre as identidades. Por isso, a necessidade de constituição de uma identidade grupal desassociada dos ex-internos do hospital psiquiátrico estaria na base do afastamento das RTs, delineando uma séria questão a ser debatida e de grande importância para os movimentos de desinstitucionalização.

Mesmo que os hospitais psiquiátricos sejam fechados, permanecem as concepções que apontam a necessidade de seu funcionamento ou da criação de outros espaços semelhantes, o que se constitui uma defesa da identidade grupal, mas um enorme empecilho à desinstitucionalização, e como citado, trata de uma lógica que necessita ser revertida. Diante disso, é preciso discutir as possibilidades para essa convivência com ex- 
-internos de hospitais psiquiátricos, no sentido de garantir a coexistência entre racionalidades opostas, uma vez que, ainda que seja mantida certa diferença entre grupos, o exercício dos direitos, entre eles o de convivência comunitária, precisa ser igualitário.

\section{Referências}

Basaglia, F. (1982). Psiquiatria alternativa: Contra o pessimismo da razão, o otimismo da prática. Conferências no Brasil (3. ed., S. Soianesi \& M. C. Marcondes, Trads.). São Paulo, SP: Brasil Debates.

Bonomo, M. (2010). Identidade social e representações sociais de rural e cidade em um contexto rural comunitário: Campo de antinomias (Tese de doutorado, Programa de Pós-Graduação em Psicologia, Universidade Federal do Espírito Santo, Vitória, ES, Brasil).

Foucault, M. (2006). Microfísica do poder (22. ed., R. Machado, Trad.). Rio de Janeiro, RJ: Graal.

Jodelet, D. (2005). Loucuras e representações sociais (L. Magalhães, Trad.). Petrópolis, RJ: Vozes.

Jovchelovitch, S. (2004). Psicologia social, saber, comunidade e cultura. Psicologia \& Sociedade, 16(2), 20-31.

Leão, A., \& Barros, S. (2008). As representações sociais dos profissionais de Saúde Mental acerca do modelo de atenção e as possibilidades de inclusão social. Saúde e Sociedade, 17(1), 95-106. doi:10.1590/S0104-12902008000100009

Leonardis, O., Mauri, D., \& Rotelli, F. (2001). Prevenir a prevenção. In F. Nicácio (Ed.), Desinstitucionalização (2. ed., pp. 65-78). São Paulo, SP: Hucitec.

Lima, M. F. de. (2005). "Nos caminhos da psicologia capixaba": Notas para a história da psicologia, da psiquiatria e da saúde pública no Estado do Espírito Santo (Dissertação de mestrado, Programa de Pós-Graduação em Psicologia, Universidade Federal do Espírito Santo, Vitória, ES, Brasil).

Maciel, S. C., Barros, D. R., Camino, L. F., \& Melo, J. R. F. de. (2011). Representações sociais de familiares acerca da loucura e do hospital psiquiátrico. Temas em Psicologia, 19(1), 193-204.

Minayo, M. C. de S. (2004). O desafio do conhecimento: Pesquisa qualitativa em saúde (8. ed.). São Paulo, SP: Hucitec.
Ministério da Saúde. (2000). Portaria 106 de 11 de fevereiro de 2000. Institui os Serviços Residenciais Terapêuticos no âmbito do SUS. Brasília, DF: Autor. Recuperado em http://dtr2004.saude. gov.br/susdeaz/legislacao/arquivo/27_Portaria_106_de_11_02_2000.pdf

Ministério da Saúde. (2011). Saúde Mental no SUS: As novas fronteiras da Reforma Psiquiátrica. Relatório da gestão 2007-2010. Brasília, DF: Autor. Recuperado em http://bvsms.saude.gov. br/bvs/publicacoes/saude_mental_fronteiras_reforma_psiquiatrica.pdf

Ministério da Saúde. (2012). Resolução $n^{\circ} 466$ de 12 de dezembro de 2012. Brasília, DF: Autor. Recuperado em http://conselho.saude.gov.br/resolucoes/2012/Reso466.pdf

Moreira, M. I. B. (2007). Se esta casa fosse minha: Habitar e viver na cidade a partir de uma residência terapêutica (Tese de doutorado, Programa de Pós-Graduação em Psicologia, Universidade Federal do Espírito Santo, Vitória, ES, Brasil).

Pacheco, J. G., Almeida, A. M. de O., \& Rodrigues, M. M. P. (2007). Representações sociais em movimento: A história de uma experiência. In M. M. P. Rodrigues \& P. R. M. Menandro (Eds.), Lógicas metodológicas: Trajetos de pesquisa em psicologia (pp. 119-150). Vitória, ES: GM.

Rivas, C. Z., \& Inostroza, A. (2003). Identidad regional em um contexto de cambio - um estúdio em La Araucania, Chile. Psicología Política, 26, 73-92.

Rocha, A. L. C. da., \& Eckert, C. (2003). Etnografia de rua: Estudo de Antropologia urbana. Iluminuras, $4(7), 1-22$.

Rotelli, F., Leonardis, O., \& Mauri, D. (2001). Desinstitucionalização, uma outra via. In F. Nicácio (Ed.), Desinstitucionalização (2. ed., pp. 1759). São Paulo, SP: Hucitec.

Venâncio, A. T. A. (2011). Da colônia agrícola ao hospital colônia: Configurações para a assistência psiquiátrica no Brasil na primeira metade do século XX. História, Ciências, Saúde - Manguinhos, 18(1), 35-52. doi:10.1590/ S0104-59702011000500003

Recebido: 13/01/2015

$1^{a}$ revisão: 16/07/2015

Aceite final: 12/08/2015 